\title{
Cheerleading Injuries and Safety
}

\section{Frederick O. Mueller, PhD}

The National Center for Catastrophic Sports Injury Research (NCCSIR) initiated a catastrophic injury (fatalities, disabilities, serious injuries) data collection system for high school and collegiate sports on a national level during the 1982-1983 school year. ${ }^{1}$ Cheerleading was not initially included until 2 collegiate cheerleaders suffered serious head injuries during the first year of data collection. Since that time, collegiate cheerleading has been associated with 31 catastrophic injuries and high school cheerleading with 73. Collegiate cheerleading accounted for $70.5 \%$ of all female catastrophic sports injuries and high school cheerleading for $65.2 \%$ of all high school female catastrophic sports injuries. Without a doubt, cheerleading is the most dangerous female sport when we look at the number of catastrophic injuries.

In 1980, the US Consumer Product Safety Commission reported an estimated 4954 hospital emergency room visits caused by cheerleading. In 2007 , the number increased to 26786 , with head and neck injuries accounting for $15.1 \%$ of these visits. Almost all of the patients with injuries (98\%) were treated and released, but in 2007, 221 cheerleaders were hospitalized, 217 were treated and transferred to another hospital, and 64 were held for observation. ${ }^{2}$ It is important to point out that data collection for cheerleading injuries has a short history, whereas football injury data collection has existed for more than 100 years. Females have also been participating in competitive sports for years, but only since 1972 and the passage of Title IX has female sport participation grown dramatically. With this increased participation has come an increase in injuries - both minor and catastrophic.

The 4 articles on cheerleading injuries in this issue of $J A T$, which use epidemiologic data collection methods, are a great start to better cheerleading injury data, but with only 1 year of data, making reliable recommendations for safety is difficult. Of these articles, the most interesting one involves potential brain injuries and selected surfaces. When a cheerleader is thrown 25 to $30 \mathrm{ft}$ in the air by athletes standing on a wood floor, an accident is waiting to happen. More research in this area is definitely needed.

So why has there been a dramatic increase in the number of cheerleading injuries, including catastrophic injuries, during the last 25 years? The answer is easy. All one has to do is compare cheerleading in 1960 with cheerleading in 2009. In the 1960s, cheerleaders were shaking pompoms, and the only stunt they performed was a short jump off the ground. Their main purpose was to get the crowd to cheer for their team: thus the word cheerleader. Cheerleading coaches in 1960 may have been ex-cheerleaders, but they were not required to have a coaching background or certification because safety was not a problem. In 2009, cheerleading is a gymnastic activity, and why it is still called cheerleading is not quite clear. It is a competitive contact sport that involves all types of gymnastic stunts, pyramids, and partner stunts as well as throwing flyers high in the air and catching them (we hope). Coaching has not kept up with the changes in cheerleading, but coaching certification programs have become available during the past 10 years. In many cases, safety issues have been associated with coaches who do not have the expertise to teach the skills that today's cheerleaders need. Cheerleading associations have also not kept up with the safety needs of the sport; if it were not for the catastrophic data collection that started 26 years ago, safety would still not be a high priority. The lesson learned in football injury data collection can also be applied to cheerleading: injuries may never be totally eliminated, but with reliable injury data collection systems, constant analysis of the data, and the development, evaluation, and dissemination of effective injury prevention strategies, these injuries can be dramatically reduced. ${ }^{1}$

There is no doubt that cheerleading injuries can be reduced if the organizations that control cheerleadingThe National Federation of State High School Associations (NFHS), the National Collegiate Athletic Association (NCAA), the American Association of Cheerleading Coaches and Administrators (AACCA), the National Council for Spirit Rules and Education, Cheer Ltd, and a number of others - take an active role in safety. A new cheerleading organization that has made great strides in promoting cheer safety is the National Cheer Safety Foundation (NCSF), founded by Kimberly Archie. The Foundation is dedicated to raising the standard of care in cheer safety to reduce injury, disability, and death from cheerleading. The NCSF has teamed with the US Sports Academy for an NCSF Cheer Education Program for coaches, athletes, administrators, and cheer enthusiasts. The program was designed by a panel of experts to prepare individuals for the challenges of managing the risks of modern cheer.

In an article published in the American Journal of Sports Medicine, Barry Boden et $\mathrm{al}^{3}$ found that of the most common stunts performed at the time of 29 cheerleading catastrophic injuries, 9 were pyramids and 8 involved the basket toss. Among the 29 catastrophic injuries, 17 were severe head injuries, resulting in 13 skull fractures and 2 deaths, and 8 were cervical fractures. To reduce injuries in cheerleading, Boden et al $^{3}$ suggested better training of spotters, mandating floor mats for complex stunts, restricting complex stunts when the surface is wet, and encouraging certification for coaches. Participation in pyramids and basket tosses should be limited to experienced cheerleaders who have mastered all other skills and should be performed with spotters and landing mats.

My recommendation for cheerleading safety and the reduction of catastrophic and other injuries is to make 
cheerleading a sport. Making cheerleading a sport will put it under the control of an athletic department, which will in turn require that it follow the rules and regulations other sports follow and provide the benefits other sports have. Some of the benefits would include qualified coaches, availability of certified athletic trainers, better practice facilities, improved medical care, and limits on practice time. There is no question in my mind that if cheerleading was declared a sport under the control of an athletic department, the number of injuries would be reduced.

The NCCSIR releases an annual report each year covering all high school and collegiate sports, with a special section on cheerleading. Cheerleading is in a special category, because in most cases it is not considered a sport. I know of only 3 colleges that consider cheerleading a sport: the University of Maryland, the University of Oregon, and Baylor University. I contacted the NCAA to see if it could provide numbers of schools at which cheerleading is considered a sport or where cheerleading is under the athletic department umbrella, but because cheerleading is not an NCAA championship sport, the information was not available. At the high school level, approximately 20 to 25 states list high school cheerleading as a sport. Included in the NCCSIR report are the following safety recommendations:

1. Cheerleaders should have a medical examination, including a complete medical history, before they are allowed to participate.

2. Cheerleaders should be trained by a qualified coach with cheerleading certification and training in gymnastics and partner stunting. He or she should also be trained in the proper methods for spotting and other safety factors.

3. Cheerleaders should be exposed to proper conditioning programs and trained in proper spotting techniques.

4. Cheerleaders should receive proper training before attempting gymnastic and partner stunts and should not attempt stunts they are not capable of completing. A qualification system demonstrating mastery of stunts is recommended.

5. Coaches should supervise all practice sessions in a safe facility.

6. Mini-trampolines and flips or falls off pyramids should be prohibited.

7. Pyramids that are over 2 people high should not be performed, and 2-high pyramids should not be performed without mats and proper spotting.

8. If it is not possible to have a physician or certified athletic trainer at games and practice sessions, emergency procedures should be provided.

9. An emergency plan should be available in writing to everybody involved in the program, including the athletes.

10. Research concerning safety in cheerleading should continue. The NCAA has an injury data collection system in place for all sports other than cheerleading. Cheerleading should be included. The NFHS has an injury data collection system in place for a majority of its sports, and cheerleading will be included in the 2009-2010 data collection process. This is a step in the right direction.

11. When a cheerleader has experienced or shown signs of head trauma (eg, loss of consciousness, visual disturbances, headache, inability to walk correctly, obvious disorientation, memory loss), he or she should receive immediate medical attention and should not be allowed to practice or cheer without written permission from a physician.

12. The NFHS and the NCAA should make cheerleading a sport, which will place it under the same restrictions and safety rules as all other high school and collegiate sports.

13. The NFHS 2009-2010 Spirit Rules Book 4 is available from the NFHS. All coaches should be familiar with the NFHS Rules Book, should read it, and should always have it available for a reference. Collegiate coaches should have a copy of the AACCA Cheerleading Safety Manuals and be familiar with its contents.

14. Cheerleading programs should have a risk management plan and strategies to promote all aspects of safety.

15. Catastrophic cheerleading injuries can be reported to the NCCSIR at mueller@email.unc.edu or to the NCSF at www.cheerinjuryreport.com.

Cheerleading is a great sport for both females and males, and by promoting safety, it will continue to grow in participation numbers and will experience continued success. For all those associated with cheerleading programs, best wishes for a successful and safe year.

\section{REFERENCES}

1. Mueller FO, Cantu RC. Twenty-Sixth Annual Report for Catastrophic Sports Injury Research. Fall 1982-Spring 2008. Chapel Hill, NC: National Center for Catastrophic Sports Injury Research; 2008.

2. National Injury Information Clearinghouse. Cheerleading Injuries 1980-2007. Washington, DC: US Consumer Product Safety Commission/Directorate for Epidemiology; 2008.

3. Boden BP, Tacchetti R, Mueller FO. Catastrophic cheerleading injuries. Am J Sports Med. 2003;31(6):881-888.

4. National Federation of State High School Associations. 2009-10 Spirit Rules Book. Indianapolis, IN: National Federation of State High School Associations; 2009.

5. George GS. Cheerleading Safety Manual. Memphis, TN: American Association of Cheerleading Coaches and Administrators; 2006.

Editor's note: Frederick $O$. Mueller, PhD, is the Director of the National Center for Catastrophic Sports Injury Research, University of North Carolina at Chapel Hill. 